\title{
Preparation and Application of Composite Lightweight Aggregate Concrete Self-insulation Block
}

\author{
Jiansuo Ma ${ }^{1, a}$, Miaomiao Zhou ${ }^{1, b}$, Huanqin Cai ${ }^{1, c}$, Runshan Bai ${ }^{1, d}$ \\ ${ }^{1}$ Hebei University of Architecture, Zhangjiakou, Hebei, China \\ ahbmjs@163.com, bzhoumiaomiao345@163.com,,zjkchq@163.com, ${ }^{\mathrm{d}}$ shsbrsh@163.com
}

\begin{abstract}
Keywords: Composite Lightweight Aggregate Concrete, Self-insulation Block, Preparation, Application

Abstract. The composite lightweight aggregate concrete self-insulation block is prepared by pumice, polystyrene particles and other materials. The self-insulation block has dumbbell-shaped hole filled with polystyrene foam. Its preparation and molding process are studied in the test. The self-insulation blocks are applied to infilled walls in frame structure. The results show that the self-insulation block of composite lightweight aggregate concrete is with the hollow rate of 54.1\%, heat resistance of $2.177\left(\mathrm{~m}^{2} \cdot \mathrm{K}\right) / \mathrm{W}$, a density of $642.29 \mathrm{~kg} / \mathrm{m}^{3}$, compressive strength of 3.96MPa. The self-insulation blocks meet exterior wall energy requirements and mechanical requirements in severe cold zones and the blocks are suitable for application.
\end{abstract}

\section{Introduction}

Wall self-insulation block is the functional block which is taken a number of effective measures to improve the thermal insulation properties on the basis of ordinary concrete block, namely the block with a single wall of the masonry system (self-insulation wall) which is both thermal insulation and retained in wall structure[1]. As one of the new building materials for promotion in wall reform, self-insulation concrete block has the advantages of energy saving, land saving, waste utilization, environmental protection and higher labor productivity, etc.[2].

Thermal insulation materials are supposed to be affixed in the surface of existing concrete blocks leading to more difficult construction, more waste in materials, significantly increasing in cost, poorer thermal insulation properties and mechanical properties. As multifunctional wall materials, integrating the performance of thermal insulation, energy saving, utilizing waste with self-bearing loads together, self-insulation blocks replace the clay bricks. Aiming to apply to cold areas as Zhangjiakou for example, the new lightweight aggregate concrete self-insulation block is designed and prepared in a way of calculating their thermal resistance and making the preparation by using natural materials and industrial waste. And mechanical properties and density of the self-insulation block is analyzed in the test.

\section{Features of Composite Lightweight Aggregate Concrete Self-insulation Block}

Material Features. According to local conditions, self-insulation blocks make good use of rich resources of pumice sand in Zhangjiakou, and extensively use industrial wastes of fly ash, while adding an appropriate amount of polystyrene particles to be the raw materials. The prepared composite lightweight aggregate concrete has small bulk density, low thermal conductivity and high strength. In low prices and low thermal insulation coefficient, the waste polystyrene foam is selected to be wrapped in composite lightweight aggregate concrete for good fireproof performance. Almost all the materials are beneficial to energy saving, waste utilization and environmental protection.

Structural Features. The energy saving requirements for Zhangjiakou reach the goal of 50\% in facades. So thermal resistance should be no less than $2.0\left(\mathrm{~m}^{2} \cdot \mathrm{K}\right) / \mathrm{W}$. According to the standard of GB50189-2005[3], if shape coefficient is larger than 0.3, the heat transfer coefficient limit of exterior wall in Zhangjiakou is $0.45 \mathrm{~W} /\left(\mathrm{m}^{2} \cdot \mathrm{K}\right)$. The external dimensions of self-insulation block are chosen to be $390 \mathrm{~mm} \times 260 \mathrm{~mm} \times 150 \mathrm{~mm}$. The self-insulation block can be used to fill the external walls or sub-chamber household partition walls in the structure system of frame structure, frame 
shear wall structure and slab-column structure.

Lightweight porous insulation materials are filled in the core of the block. The outer wall and the core are as a whole in pouring concrete together for molding, which are in good connection. The "dumbbell-shaped" structure not only reduces the weight of the block but also provides good effect of thermal insulation compared to solid blocks, achieving double benefits. Besides, the insulation materials or other flammable insulation materials are "built-in" in the hole, which effectively reduces the risk of fires. The rib is "triangle" in shape, providing a better load-bearing and load transmission between the block, enhancing the overall strength and stability of masonry walls [4]. As is shown in Figure 1, 1 represents an outer wall, 2 the ribs, 3 the filled polystyrene foam.

Small rectangular parallelepiped type of the self-insulation block is commonly used in blocks for convenience to construction. To ensure good mechanical performance, the unique hollow hole is designed as "dumbbell-shaped" hole. The load-bearing member is cooperative in force with the masonry block, having mutual deformation under earthquake, improving the seismic performance. Hollow rate of the self-insulation block is up to $50 \%$, meeting the energy saving requirements. Filled with insulation materials in the hollow hole and tightly bonded together with the outer wall of lightweight aggregate concrete, the block is an integration. The lightweight aggregate concrete self-insulation is easy to produce with low manufacturing cost and easy for promotion and application.

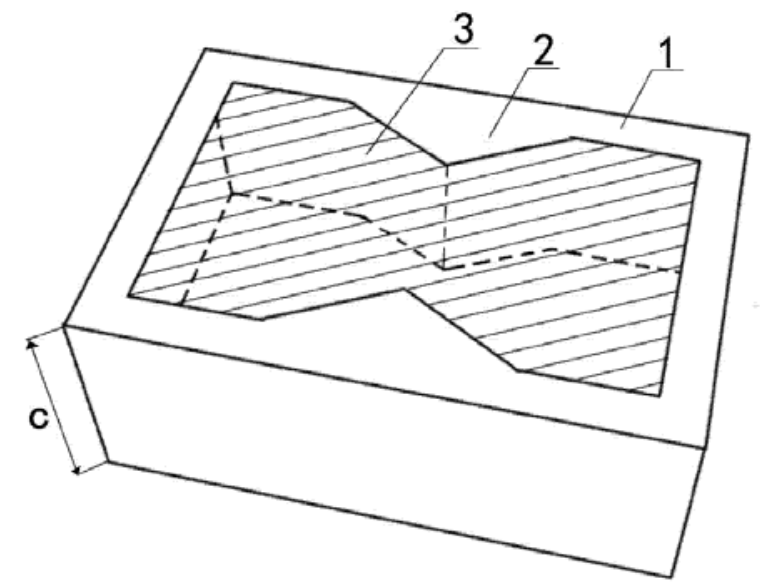

Fig.1 The schematic diagram of self-insulation block

\section{Preparation of Composite Lightweight Aggregate Concrete Self-insulation Block}

Preparation Process. By choosing the rational composite materials in special preparation process, the self-insulation block is light and sound insulation. The test mixed fly ash, pumice sand, polystyrene particles and cement together to make preparation for composite lightweight aggregate concrete. Placing polystyrene board into the core of the block, the self-insulation block is produced by the process of vibration pouring molding. The key of preparation is the self-compacting of composite lightweight aggregate concrete and great mold in accurate size.

In accordance with preliminary experiments results, it is determined the best mix proportion as follows. Fly ash: pumice sand: polystyrene particles: water $=1: 0.43: 0.935: 0.004: 0.64$. By advance, the mold is designed and prepared based on block type and hole type of self-insulation block. Using bamboo plastic template, the outer template is fixed with small square beams in the surface of the outer templates. As to thermal insulation materials, polystyrene board is the internal template and does not need to remove from the the block after molding. The designed outer template of self-insulation block is with dimensions of $388 \mathrm{~mm} \times 258 \mathrm{~mm} \times 150 \mathrm{~mm}$, smaller than true block dimensions, for eliminating the effects of mold inflation when vibrating. It can be seen from figure 2 that cement, fly ash, pumice sand, polystyrene particles are mixed together in proportion. After adding some water, the mixtures are stirred and poured into a customized mold. The mixtures are followed by vibrating for 1-2 minutes in the vibration table. And form removal is conducted 
after the process of pouring concrete for 36 hours. The self-insulation block has been produced when conserving for more than 7 days under standard conditions.

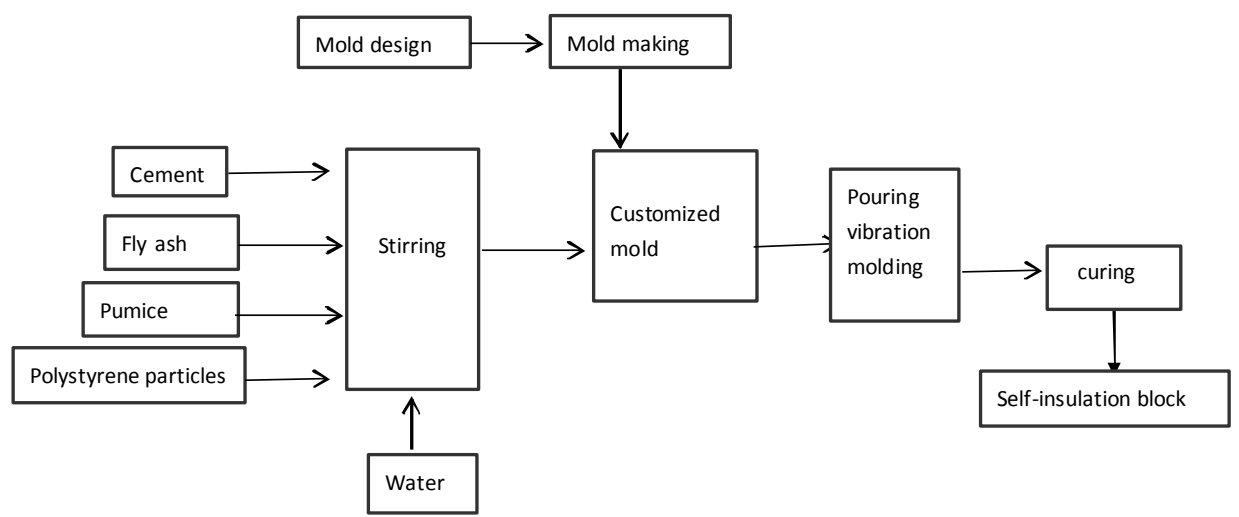

Fig.2 Preparation process of self-insulation block

Performance. The hollow rate is tested to be $54.1 \%$. Weighing the monolithic self-insulation block, the average mass is $9.77 \mathrm{~kg}$. The measured density of self-insulation block is $642.29 \mathrm{~kg} / \mathrm{m}^{3}$. It is not heavy for construction workers to operate in masonry.

The strength of the block mainly depends on the strength of composite lightweight aggregate concrete, the block type and hollow rate of the block. The compressive strength of block is tested by 2000KN hydraulic pressure testing machine. The measured compressive strength of self-insulation block comes to be 3.96MPa, larger than the self-bearing load requirement of $2.5 \mathrm{MPa}$.

\section{Engineering Application}

The self-insulation blocks are applied in a mall in Zhangjiakou city which is a frame structure. The building shape coefficient is greater than 0.3. Most of infill walls are built by the self-insulation blocks while some others are built by ordinary hollow blocks as a comparison. Along one side each block is placed and shall be staggered between two layers of the blocks. Each vertical gray leather block joints should be staggered. Rachel steel bars are in the masonry along every 600mm of masonry in the height and then hew is extended to window and door openings. The connection between the block with the thickness of $10 \mathrm{~mm}$ is filled with cement mortar in a thermal conductivity of $0.87 \mathrm{w} /(\mathrm{m} \cdot \mathrm{k})$, internal wall surface using lime mortar in a thermal conductivity of $0.81 \mathrm{w} /(\mathrm{m} \cdot \mathrm{k})$ with the thickness of $20 \mathrm{~mm}$, external wall surface using insulation mortar in a thermal conductivity of $0.29 \mathrm{w} /(\mathrm{m} \cdot \mathrm{k})$ with the thickness of $20 \mathrm{~mm}$. The thermal resistance of self-insulation block filled wall comes to be $2.177\left(\mathrm{~m}^{2} \cdot \mathrm{K}\right) / \mathrm{W}$, while ordinary hollow block filled wall $1.78\left(\mathrm{~m}^{2} \cdot \mathrm{K}\right) / \mathrm{W}$. The self-insulation block is convenient for masonry, outstanding in insulation effect, meeting the requirements of building energy efficiency.

\section{Conclusion}

Energy conservation and load-bearing factors are directly influenced by different forms of hole types of the blocks, and the hole type is the theoretical basis of designing the self-insulation block. The designed "dumbbell-shaped" hole of the block is filled with polystyrene foam, keeping good insulation, reducing the weight of the block, increasing the strength of the block for the triangular rib.

The prepared composite lightweight aggregate concrete self-insulation block is with dimensions of $390 \mathrm{~mm} \times 260 \mathrm{~mm} \times 150 \mathrm{~mm}$, monolithic mass of $9.77 \mathrm{~kg}$, hollow rate of $54.1 \%$, the thermal resistance of $2.177\left(\mathrm{~m}^{2} \cdot \mathrm{K}\right) / \mathrm{W}$, density of $642.29 \mathrm{~kg} / \mathrm{m}^{3}$, compressive strength of $3.96 \mathrm{MPa}$, meeting the requirements of energy saving and mechanical properties in cold region from this study. The composite lightweight aggregate concrete self-insulation blocks are suitable for application. 


\section{Acknowledgements}

This research was financially supported by the National Science Foundation of Hebei province(E2012404004).

\section{References}

[1] Wei Zhang, Daosheng Sun, and Yi Ding: New Building Materials. Vol. 36(1)(2004), P. 13-15.(In Chinese)

[2] Xiaoyan Ding, Yonglei Luo, and Fanzhong Chen, Journal of Southeast University(Natural Science Edition). Vol. 45(1)(2015), P. 145-150.(In Chinese)

[3] GB50189-2005 Design standard for energy efficiency of public buildings.(In Chinese)

[4] Jiansuo Ma, Runshan Bai, Huanqin Cai and Cheng Li, China. Patent 201420631942.5.(2014)(In Chinese) 